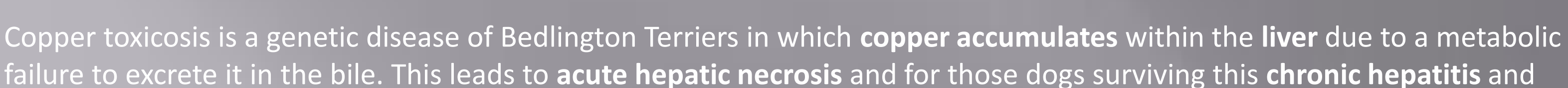
dirrhosis. In the acute phase or form of the disease there is hamemolyticic anaemia, adding pre-hepatic jeundice to any existing

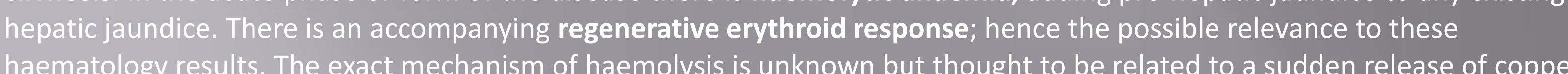

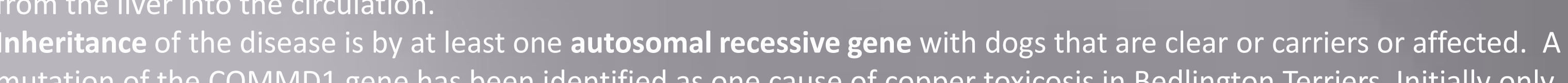
dentifiable indiriectly by a marker test, since 2005 it has been possible to screen for this mutation by a DNA test.

\title{
Asymptomatic Reticulocytosis in a Family of Bedlington Terriers
}

MUPPEY

Female (neutered), born Nov. 2005.

Grandmother to Liffey but unrelated to Izzy.

16/05/2018 blood test due to pica (eating compost) $\mathrm{RBC}=7.86 \times 10^{12} / \mathrm{L}$

Absolute Reticulocyte Count $=187 \times 10^{9} / \mathrm{L}$

29/05/2018 x-ray chest, scan liver, spleen \& kidneys NAD

bile acid stimulation test $=$ Not significantly abnormal $\mathrm{RBC}=6.99 \times 10^{12} / \mathrm{L}$

Absolute Reticulocyte Count $=158 \times 10^{9} / \mathrm{L}$

07/06/2018 further blood test to check for resolution $\mathrm{RBC}=8.27 \times 10^{12} / \mathrm{L}$

Absolute Reticulocyte Count $=172 \times 10^{9} / \mathrm{L}$

04/03/2019 poor appetite, blood test, no specific

$\mathrm{RBC}=8.38 \times 10^{12} / \mathrm{L}$

Absolute Reticulocyte count $=211 \times 10^{9} / \mathrm{L}$

22/11/2019 upper resp. tract noise, no specific diagnosis

$\mathrm{RBC}=7.86 \times 10^{12} / \mathrm{L}$

Absolute Reticulocyte Count $=154 \times 109 / \mathrm{L}$

23/12/2019 bilious and retching, pancreatitis

$\mathrm{RBC}=7.96 \times 10^{12} / \mathrm{L}$

Absolute Reticulocyte Count $=153 \times 10 \% / \mathrm{L}$

CONCLUSIONS

There are no conclusions.

Reticulocy tosis in Bedlington terriers can be a symptom of Copper toxicosis due to a regenerative response to haemolysis. However all of these dogs have tested negative for the disease genetically and there were no consistent symptoms or blood test results to suggest hepatic disease in any of them. It has been speculated that the gene identified in the current test is not the whole story and that another gene or genes may be involved. It is possible that these dogs have a partial problem with copper metabolism and abnormally high serum copper levels resulting in some ongoing haemolysis that is compensated for by a regenerative response. But there were no signs typical of haemolysis in their blood smears.

It is possible that their reticulocyte maturation process is different to other dogs; with a longer period of development in the blood stream than usual, meaning there are more to be seen and counted in any sample.

It may simply be an idiosyncratic finding and even the fact that they are related a coincidence. In the absence of associated clinical disease and bearing in mind that these were clinical cases not research animals, no further testing was performed and their reticulocytosis considered as an incidental finding, in other words, "normal for them".

But it remains a potential area of enquiry if other Bedlington terriers have similar haematology.

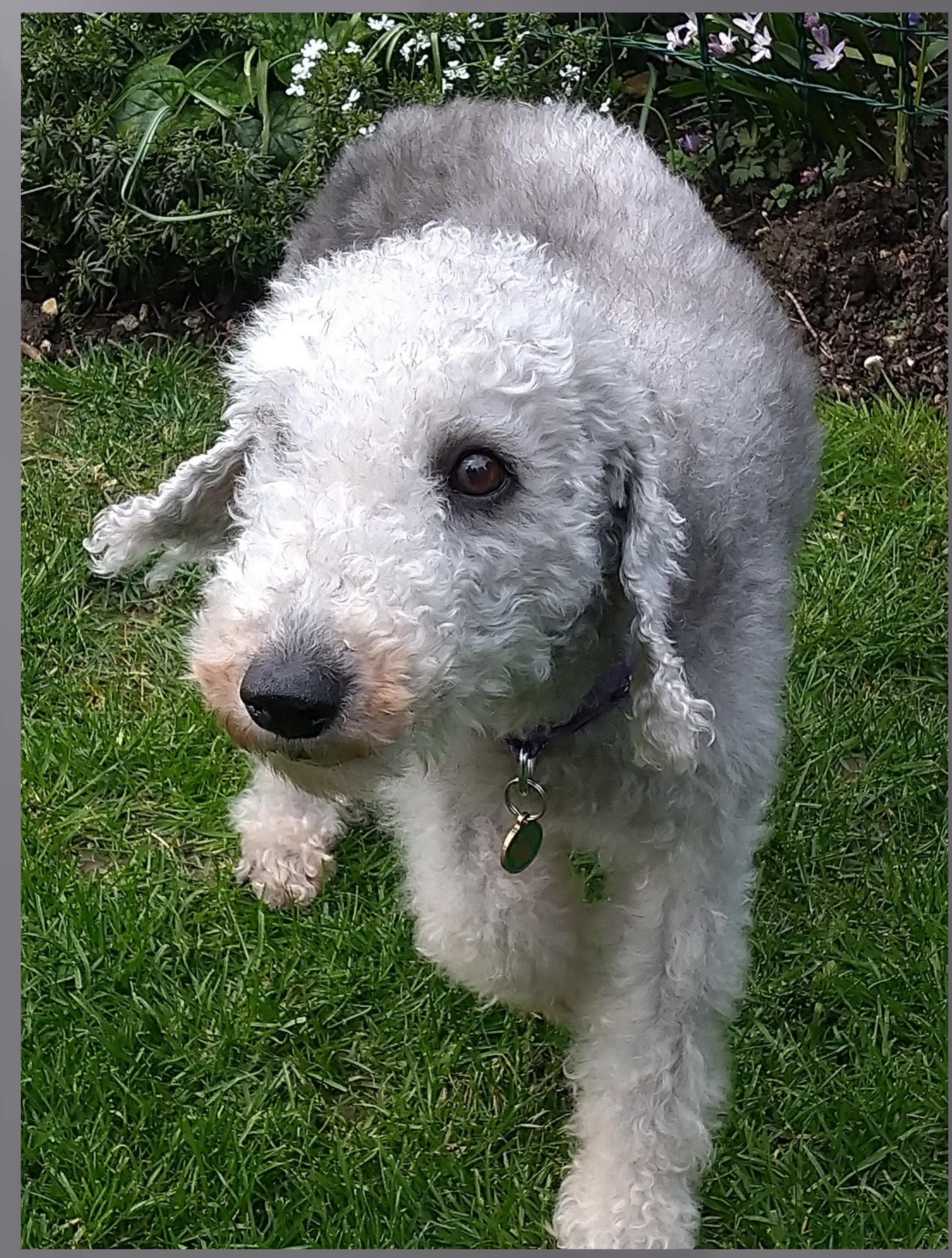

Eched by the kidneys. This secretion is in response to renal tisste hypoka. Retichocytes are created in the penutimate step of red cell maturation. They are released from the bone marrow

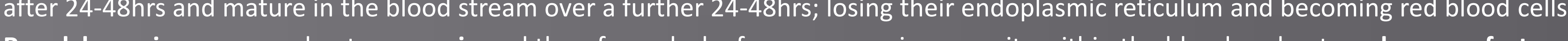
Fen

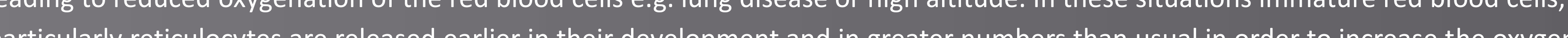
.

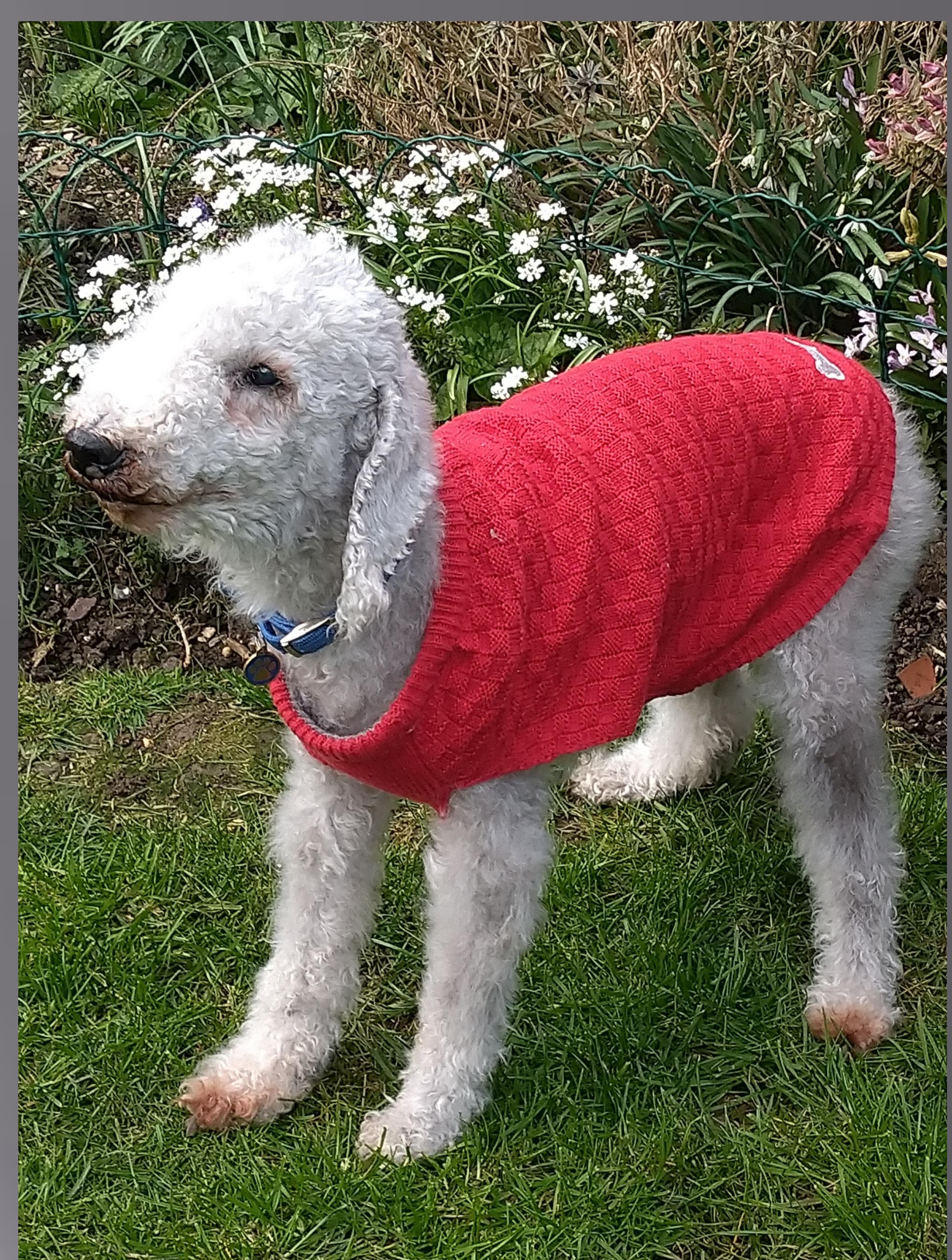

IZZY

Female (neutered), born Feb. 2010

Mother of Liffey, but unrelated to Muppey

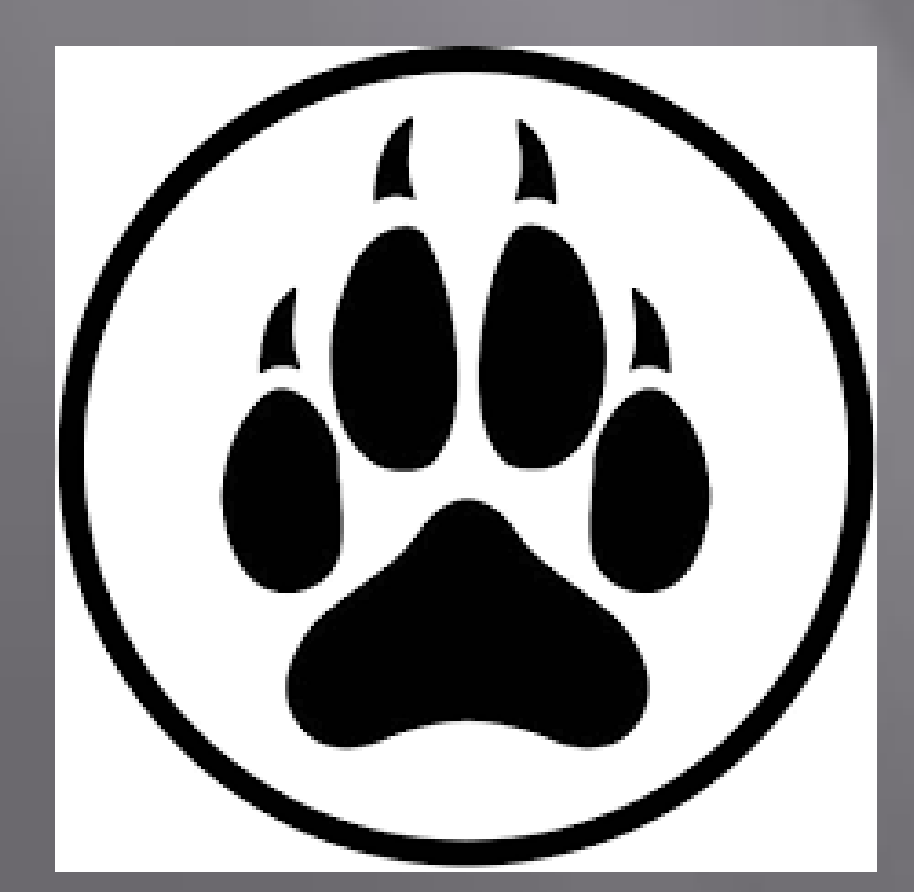

$15 / 06 / 2018$ routine pre-dental blood test

$\mathrm{RBC}=8.07 \times 10^{12} / \mathrm{L}$

Absolute Reticulocyte Count $=145 \times 10^{9} /$

In the light of prior knowledge of another senior Bedlington terrier,

unrelated but in the same household, with asymptomatic reticulocytosis and in the absence of any clinical illness or other significant findings no further investigation was undertaken.

11/02/2020 blood test to investigate polydipsia $\mathrm{RBC}=7.26 \times 10^{12} / \mathrm{L}$

Absolute Reticulocyte Count $=115 \times 10^{9} / \mathrm{L}$

$19 / 02 / 2020$ blood test to assess clinical anaemia $\mathrm{RBC}=2.38 \times 10^{12} / \mathrm{L}$

Absolute Reticulocyte Count $=95 \times 10^{9} / \mathrm{L}$

20/02/2020 Izzy was put to sleep due to an invasive adrenal tumour and gastro-intestinal bleeding

LIFFEY

Female (neutered), born April 2012.

Granddaughter of Muppey and daughter of Izzy

20/07/2018 routine pre-dental blood test. $\mathrm{RBC}=8.04 \times 10^{12} / \mathrm{L}$

Absolute Reticulocyte Count $=171 \times$ $10^{9} / \mathrm{L}$

Given the knowledge of reticulocytosi in grandmother and mother with no clinical illness or other significant findings no further investigation was undertaken.

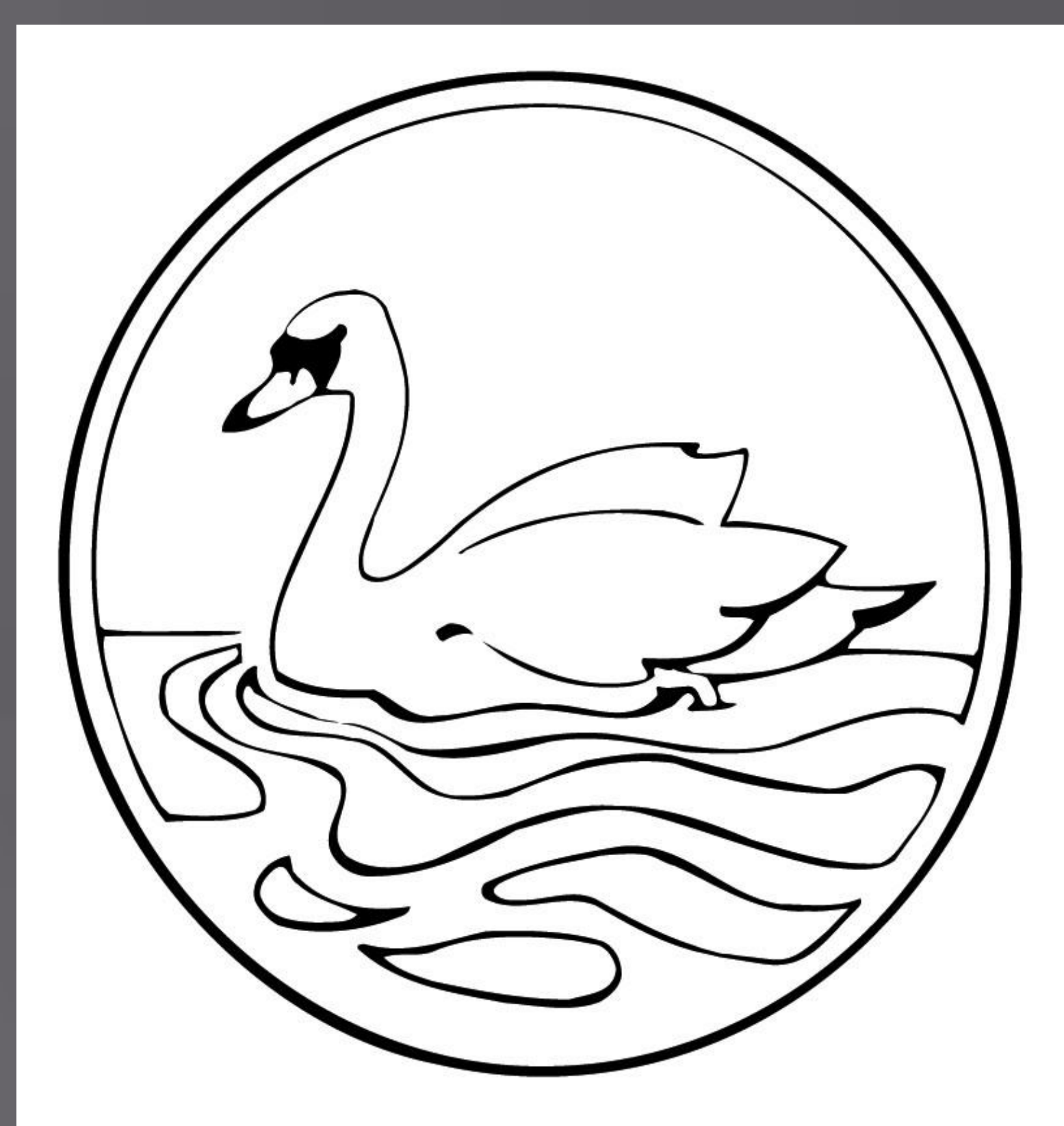

\section{Footnote}

This poster was prepared for BSAVA 2020. While in preparation a fourth Bedlington Terrier in the same household was shown to have asymptomatic reticulocytosis.

GERTIE

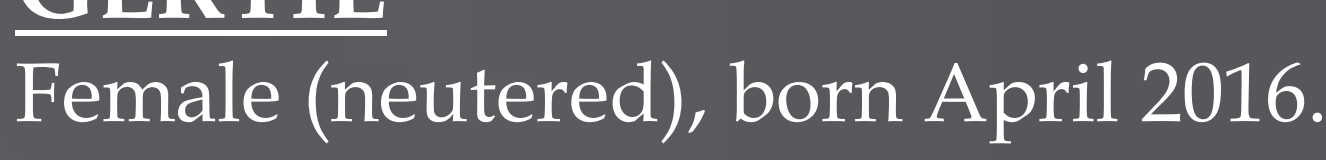

No relation to any of the other 3 dogs.

12/02/2020 blood test as part of routine health check.

$\mathrm{RBC}=7.29 \times 10^{12} / \mathrm{L}$

Absolute Reticulocyte Count $=156 \times 10^{9} / \mathrm{L}$

Again in the absence of any clinical symptoms

no further investigation was undertaken.

John R Bowie BVMS MRCVS Swanspool Veterinary Clinic Wellingborough

Northamptonshire

NN8 2BT 